\author{
DOROTA WALCZAK* \\ Uniwersytet Warszawski, Warszawa \\ ORCID: 0000-0002-0182-6256
}

\title{
MIĘDZY TRADYCJĄ A NOWOCZESNOŚCIĄ. IKONY ROSYJSKIE W XIX WIEKU
}

W historii sztuki przez długie lata pokutował stereotyp o tym, że rosyjskie malarstwo ikonowe XIX w. było wtórne i mało interesujące dla badaczy. Uczeni poniekąd dali się uwieść rosyjskim autorom II połowy XIX w., którzy nierzadko poddawali gruntownej krytyce współczesne im malarstwo ikonowe, tym bardziej, że wśród krytycznie nastawionych autorów byli i klasycy literatury rosyjskiej, jak Wissarion Bieliński, Nikołaj Leskow czy Fiodor Dostojewski. Pamiętać jednak należy, że w rzeczywistości obiektem krytyki wymienionych wyżej twórców kultury było nie całe rosyjskie malarstwo ikonowe, a tylko jego niewielka, chociaż rzucająca się w oczy i bardzo rozpowszechniona, część - tzw. „raschożyje” ikony, przeznaczone dla „masowego odbiorcy”. Całościowy obraz rosyjskiego malarstwa ikonowego XIX w. jest zdecydowanie bardziej skomplikowany i przeplatają się w nim płynnie tradycja i współczesność, i to nie tylko na poziomie refleksji teologicznej, ale także na poziomie wykonania artystycznego, tym bardziej, że dla XIX w. charakterystyczna jest ciągle pogłębiająca się różnica pomiędzy ikoną ludową i estetyką elit intelektualnych ${ }^{\mathrm{I}}$.

Trzeba koniecznie wspomnieć o tym, że już od XVI w. kult ikon na Rusi przyjmował ogromne rozmiary, i to w znaczeniu całkowicie dosłownym. Za wzrastającym zapotrzebowaniem na ikony z różnym skutkiem starali się nadążać i ikonopiscy. Jeżeli aż do początków XVI w. ten sam malarz ikon wykonywał ikonę od początku do końca, to od XVI stulecia na ziemi suzdalskiej pojawiają się całe wsie, w których większość ludności zajmowało się malarstwem ikonowym. Wśród owych wsi najbardziej istotnymi z punktu widzenia niniejszego opracowania były Włodzimierz, Bogolubowo, Suzdal, Juriew Polski, Szuja, Murom, Wiazniki, Palech, Chołuj i Mstera. Rosyjska historyk sztuki Wiera Briusowa w swojej monografii poświęconej rosyjskiemu malarstwu ikonowemu XVII w. utrzymuje, że w Palechu i Msterze masowa produkcja ikon metodą manufakturową rozpoczęła się już w XVII stuleciu².

\footnotetext{
* Walczak Dorota - magister historii (2015), historii sztuki (2016) i filologii rosyjskiej (2018). Od 2015 r. doktorantka na Wydziale Historycznym Uniwersytetu Warszawskiego. Jej zainteresowania naukowe to rosyjskie malarstwo ikonowe XIX i XX wieku i historia myśli religijnej, filozoficznej i estetycznej w Rosji, e-mail: dorota. walczak@student.uw.edu.pl.

1 G. Kobrzeniecka-Sikorska, Ikona, kult, polityka. Rosyjskie ikony maryjne od drugiej połowy XVII wieku, Olsztyn 2000 , s. 150 .

2 В. Г. Брюсова, Русская живопись XVII века, Москва 1986, s. 7-9.
} 
Istota pracy manufakturowej nad ikoną polegała na tym, że ikonopisiec-rzemieślnik wykonywał nie cały wizerunek, a tylko jedną konkretną czynność - przykładowo, przygotowywał deskę pod ikonę, nanosił na nią złocenia, pisał detale architektoniczne, szaty lub twarze przedstawianych postaci (tzw. licznik). Proces przygotowania ikony manufakturowej został po mistrzowsku opisany przez Maksyma Gorkiego w drugim tomie jego autobiograficznej trylogii pt. Wśród ludzi (ros. В людяx). Gorki, który w latach 90. XIX w. przez pewien czas pracował w warsztacie ikonopisarskim nad górną Wołgą, utrzymywał, że nad jedną ikoną mogło pracować nawet dziesięciu mistrzów i bardzo negatywnie oceniał manufakturowy sposób pracy. „Malarstwo ikonowe nikogo tu nie interesuje; jakiś zły mędrzec rozbił ich trud na długi szereg działań, pozbawionych piękna, niezdolnych do wzbudzenia miłości do pracy, zainteresowania nią" - pisał wyraźnie rozgoryczony autor ${ }^{3}$. Dane przywołane przez wybitnego historyka sztuki Nikodima Pawłowicza Kondakowa pokazują, że w samym tylko Palechu pod koniec XIX w. „produkowano” (bo trudno tu użyć innego określenia) około miliona ikon rocznie 4 .

Nie byłoby to możliwe, gdyby nie fakt, że w XIX w. pojawiają się różne „,nowinki techniczne", które z biegiem czasu pozwoliły znacznie usprawnić i skrócić proces pracy nad ikoną. Na miejsce pracochłonnego i zajmującego dużo czasu złocenia na pulment, upowszechnia się tak zwany mikstion ${ }^{5}$. W odróżnieniu do pulmentu, mikstion schnie nie kilka dni, a jedynie kilka godzin. Dzięki wykorzystaniu mikstionu można napisać ikonę i wykonać na niej złocenia w przeciągu jednego dnia roboczego. Szybkie tempo pracy nad ikoną, rzecz jasna, odbiło się na jej jakości artystycznej. Wiele powstających w XIX w. ikon charakteryzowało się niechlujnością, niedokładnością rysunku i licznymi uproszczeniami. Tego typu ikony nazywano popularnie „ikonami ludowymi”, „krasnuszkami” lub „,raschożymi ikonami”。.

Innym XIX-wiecznym masowym zjawiskiem stały się także ikony drukowane. W odeskich, a potem także w moskiewskich fabrykach, poczynając od lat 70. XIX w., rozpoczyna się druk barwnych litografii, które były potem naklejane na deski lub na blachę metalową i były sprzedawane za wiedzą i zgodą Rosyjskiej Cerkwi Prawosławnej’. Pierwotnie dwie takie fabryki-drukarnie zostały otwarte w Odessie przez Tila i Fiesienko, w latach 90. XIX w. dołączają do nich moskiewscy fabrykanci Żako i Bonaker. Pojawienie się tanich i masowych ikon drukowanych miało, według większości wersji, stać się jedną z głównych przyczyn kryzysu w rosyjskim malarstwie ikonowym. W liście napisanym do cara Mikołaja II ikonopiscy z Palecha, Mstery i Chołuja skarżą się, że „w połowie lat 90. XIX w. w Moskwie pojawiły się niemal równocześnie dwie zagraniczne firmy panów Żako i Bonakera, którzy, zacząwszy od wykonywania pudełek do pasty do butów, [...] przerzucili się na drukowanie

\footnotetext{
М. Горький, Детство; В людях; Мои университеты, Москва 1973, s. 317.

4 О. Ю. Тарасов, Икона и благочестие. Очерки иконного дела в Императорской России, Москва 1995, s. XIV.

Zob. Л. П. Шмидт, Золочение, серебрение и бронзирование по дереву, Москва 1903.

O „raschożych” ikonach w Rosji zob.: О. Ю. Тарасов, „Расхожсая” икона в русской художественной культуре XVIII - начала ХХ века, w: Культура средних веков и Нового времени, Москва 1987, s. 80-85.

O historii ikon drukowanych w Rosji zob.: R. Nichols, The Icon and the Machine in Russia's religious Renaissance, w: Christianity and the Arts in Russia, red. W. Blumfield, Cambridge 1991, s. 131-144.
} 
maszynowe na blasze cynkowej kopii cudownych ikon”" Według autorów listu, ,ikony owe wzbudziły moralny zamęt wśród rosyjskiego ludu, gdyż naruszyły wśród najbardziej wrażliwych ludzi prawosławnych uczucia religijne", jako że początkowo były sprzedawane obok innych towarów produkowanych przez fabrykantów, a co gorsza, stanowiły nierówną konkurencję dla ikon rzemieślniczych, gdyż, charakteryzując się zdecydowanie niższą ceną, w sposób znaczący obniżyły ceny ikon pisanych ręcznie.

Wydaje się wielce prawdopodobne, że to właśnie w ramach konkurencji cenowej z ikonami drukowanymi w połowie XIX w. w Rosji pojawia się jeszcze jedno zjawisko, które z czasem stanie się niechlubnym symbolem XIX-wiecznych ikon - tzw. ,ikony podokładnicowe” (ros. «фолежная икона» lub «подфолежная икона»). Na pierwszy rzut oka ,foleżnaja ikona” wydaje się zwykłą ikoną w metalowej ryzie, ale po zdjęciu okładu okazuje się, że te części wizerunku, które pozostawały zakryte okładem, są albo wykonane bardzo niechlujnie, albo wcale ich nie ma. Jak zauważali członkowie powstałego w I9or r. Komitetu Troski o Rosyjskie Malarstwo Ikonowe, „w rozpaczliwej walce o byt ikonopiscy nie mogli być wybredni przy wyborze środków, i rzeczywiście obniżyli koszty swojej produkcji, zrównali ceny ikon pisanych ręcznie z drukowanymi [...] poprzez obniżenie nie tylko artystycznego, ale nawet czysto rzemieślniczych walorów ikon do takiego poziomu, poniżej którego chyba nic już znajdować się nie może. Najpierw pisali na ikonach jedynie twarze i ręce, zakrywając resztę tanią blachą, a następnie dekorowali ikonę papierowymi kwiatami i zamykali ją za szkłem kiotu; w ostatnim czasie jednak przestali oni prawie całkowicie pisać nawet twarze, wycinając je z drukowanych obrazków i jedynie naklejając na deskach"ıo.

Warto wspomnieć, że obraz rzemieślniczego palechskiego i msterskiego malarstwa ikonowego jest zdecydowanie bardziej skomplikowany i niejednoznaczny. Równocześnie z omówionymi wyżej tanimi ikonami, przeznaczonymi dla masowego „odbiorcy”, na Suzdalszczyźnie powstawały na zamówienie ikony zupełnie innego rodzaju, które z kolei charakteryzowały się bardzo skomplikowaną kompozycją, bogactwem detali i ornamentów, a często także i rozwiniętym pejzażem na drugim planie. Tego typu ikony, choć nieporównanie doskonalsze pod względem artystycznym, są również dość problematyczne z punktu widzenia teologii ikony, gdyż ze względu na wielopostaciowość trudno się na nich dopatrzyć jednej konkretnej postaci świętego, do której wierny mógłby się zwrócić ze swoją modlitwą.

Chociaż, jak widać, w palechskim, msterskim i chołujskim malarstwie ikonowym przejawiają się także nowe tendencje formalno-stylistyczne, rzemieślnicze ośrodki ikonopisarskie pozostają główną twierdzą ikonopisarskich tradycji. W drugiej połowie XIX w. w związku z pojawieniem się w Rosji (tak jak i w całej Europie) mody na „starożytności”, w Palechu, Msterze i Chołuju można było zamówić również ikony utrzymane w stylistyce różnych szkół - praktycznie rzecz biorąc, w stylu dowolnej „,szkoły historycznej”. Warsztaty palechskie często realizowały zamówienia staroobrzędowców, którzy chcieli mieć w domu ikony zbliżone do ikon, pisanych jeszcze przed reformami Nikona i rozłamem w rosyjskiej Cerkwi Prawosławnej, choć w latach 6o. XIX w. ich zleceniodawcami stają się także różnej maści słowianofile i miłośnicy kultury staroruskiej.

\footnotetext{
8 Высочайше учрежденный Комитет попечительства о русской иконописи и его задачи, Санкт-Петербург 1907, s. 7.

9 Ibidem.

10 Ibidem, s. 31.
} 
„Historyzujące ikony” stoją niejako w opozycji do funkcjonujących w głównym nurcie „ikon malarskich”. W XVIII w. w szeregu największych rosyjskich miast, przede wszystkim w Petersburgu i w Moskwie, pod wpływem zachodnioeuropejskiego malarstwa realistycznego, powstaje zjawisko ,ikony malarskiej”. Już w połowie XVII w. wielu ikonopisców w swoich pracach zaczyna wykorzystywać środki artystyczne charakterystyczne nie dla malarstwa ikonowego, ale dla malarstwa - modelunek światłocieniowy i portretowość. Niekiedy ikonopiscy wykorzystują farby olejne w miejsce tradycyjnej tempery jajowej. Zdaniem polskiej historyk sztuki Barbary Dąb-Kalinowskiej w XVII w. w Rosji wręcz ginie rozumienie teologii ikony ${ }^{\text {II }}$. Już Simon Uszakow na swojej ikonie Mandylionu tak naprawdę stworzył portret Chrystusa, lecz autorem pierwszej prawdziwie portretowej ikony pozostaje malarz Sieriebriakow, który w I826 r. namalował portret świętego Serafina z Sarowa, który stał się podstawą późniejszej ikonografii tej postaci. G. Kobrzeniecka-Sikorska pisze, że w XIX w. w Rosji drastycznie zwiększa się przepaść pomiędzy sztuką „elitarną” i „prowincjonalną”. „W tym ogromnym mocarstwie, jakie stanowiła ówczesna Rosja, tylko trzy miasta były wielkimi metropoliami: Petersburg, Moskwa i Odessa. W zasadzie tylko tutaj powstawała sztuka świecka, przynależąca do europejskiej" - uważa polska badaczka' ${ }^{\text {12 }}$. B. Dąb-Kalinowska zauważa, że „ogólnochrześcijańskie lub katolickie w charakterze obrazy dekorowały powstałe na początku XIX w. liczne budowle sakralne, których najbardziej reprezentacyjnymi przykładami są Sobory Matki Boskiej Kazańskiej i św. Izaaka Dalmatyńskiego w Petersburgu, a przede wszystkim cerkiew Zbawiciela w Moskwie"ı.

Rosyjskie malarstwo religijne pojawia się w połowie XIX w. Za pierwszy rosyjski obraz akademicki o tematyce religijnej jest uważane Objawienie się Chrystusa ludowi pędzla Aleksandra Iwanowa. Dzieło owo powstawało niemal dwadzieścia lat, od I837 do I857 r. Monumentalne płótno Iwanowa wzbudziło podziw współczesnych, a wśród nich także Nikołaja Gogola, Aleksandra Hercena i Nikołaja Czernyszewskiego ${ }^{14}$. Kompozycyjnie Objawienie sie Chrystusa ludowi nie ma nic wspólnego z kanonami ikonowymi. Jak pisze historyk sztuki M. M. Allenow, na tym obrazie teologicznie ukazano znaczenie pojawienia się Chrystusa nie jako pielgrzyma na pustynnej drodze, ale jako moment początku nowego świata, co zostało wyrażone przez Jana Chrzciciela, który pokazywał palcem przybliżającego się Jezusa' ${ }^{15}$. Za przykładem Iwanowa poszli także i inni rosyjscy artyści, wśród których najbardziej znanymi byli Nikołaj Ge i Iwan Kramskoj. Według polskiej badaczki Barbary Stempczyńskiej, Kramskoj i Ge wielokrotnie udowadniali, że motywy ewangeliczne stały się dla nich jedynie pretekstem dla wyrażania własnych koncepcji filozoficznych i teologicznych ${ }^{16}$.

Zdaniem B. Dąb-Kalinowskiej tradycyjne rozumienie teologii ikony zanika w Rosji w momencie pojawienia się tzw. ikon malarskich. Jeden z najbardziej znanych artystów z kręgu Orużejnej Pałaty, Josif Władymirow, w połowie XVII w. napisał traktat, w którym wyraźnie opowiadał się za „,̇ywopodobiem” (realistycznym przedstawianiem człowieka)

11 B. Dąb-Kalinowska, Między Bizancjum a Zachodem. Ikony rosyjskie XVII-XIX wieku, Warszawa 1990, s. 25.

12 G. Kobrzeniecka-Sikorska, op. cit., s. 143.

13 B. Dąb-Kalinowska, Między Bizancjum ..., s. 105.

14 Н. И. Беспалова, Русские революиионные демократы и передовая художественная критика в России 1860-х годов, w: Русская прогрессивная художественная критика второй половины ХХ - начала ХХ века: Хрестоматия, ред. В. В. Ванслов, Москва 1977, s. 20-24.

15 М. М. Алленов, Александр Андреевич Иванов, Москва 1980, s. 121.

16 B.Stempczyńska, Dostojewski a malarstwo, Katowice 1980, s. 101. 
w malarstwie ikonowym. Władymirow uważał, że ikona powinna być w miarę możliwości podobna do swojego praobrazu, przy czym pod pojęciem ,praobrazu” rozumie nie jak w klasycznej teologii ikony boską naturę świętego, a jego fizyczne i materialne ciało ${ }^{\mathrm{I}}$. Ikonopisiec pragnął, aby malarze ikon przedstawiali otaczającą ich rzeczywistość i to właśnie zgodność z naturą powinna - jego zdaniem - stać się głównym kryterium oceny ikon. Wiele wskazuje na to, że z poglądami Władymirowa na malarstwo ikonowe zgadzał się m.in. wybitny teolog Symeon Połocki.

W epoce piotrowej wśród przedstawicieli rosyjskiej elity intelektualnej pojawia się zainteresowanie malarstwem religijnym o proweniencji zachodnioeuropejskiej. Owa tendencja utrzymuje się także przez całe XIX stulecie, przy czym charakterystyczne jest, że rosyjscy inteligenci nie dostrzegają praktycznie żadnej różnicy pomiędzy ikoną i obrazem religijnym. Szczególną popularnością cieszyły się wśród nich obrazy słynnego włoskiego malarza epoki quattrocento - Rafaela Santi. Rafaelowską Madonną Sykstyńską zachwycali się Aleksander Hercen, Iwan Turgieniew, Nikołaj Czernyszewski, a także Fiodor Dostojewski, który ustami jednego ze swoich bohaterów nazwał Madonnę Sykstyńską ,ideałem ludzkości”. Jak twierdzi B. Dąb-Kalinowska, obrazy Rafaela były dla rosyjskich malarzy przede wszystkim wzorami do naśladowania w malarstwie religijnym, a ich popularność można tłumaczyć faktem, że ten wybór tematów ikonograficznych, który istnieje w twórczości Rafaela, był do przyjęcia także dla władz Akademii Sztuk Pięknych i dla hierarchii cerkiewnej ${ }^{\mathrm{i}}$.

Jak już wspomniano, rosyjskie malarstwo religijne o charakterze akademickim pojawiło się stosunkowo późno, a jego powstanie jest związane z imieniem Aleksandra Iwanowa i z jego obrazem Objawienie się Chrystusa ludowi. Zachwyt, który widok owego płótna wywołał u wielu przedstawicieli rosyjskiej elity intelektualnej, i to nawet u tych, którzy byli bardzo silnie związani z prawosławiem (można tu przywołać chociażby Nikołaja Gogola, który nazywał Iwanowa geniuszem ${ }^{19}$ ), po raz kolejny udowadnia, że w owym czasie dla rosyjskich inteligentów nie było zdecydowanej różnicy pomiędzy malarstwem ikonowym a akademickim malarstwem religijnym, co nie znaczy, że wszystkie obrazy religijne znajdowały aprobatę i zrozumienie. Za przykład może tu posłużyć chociażby płótno innego rosyjskiego malarza, Nikołaja Gaya Ostatnia wieczerza. Obraz ten wywołał skandal na wystawie w petersburskiej Akademii Sztuk Pięknych w I963 r. Dziennikarze gazety „Sowriemiennaja letopis" " wskazywali, że obraz nosi ,nieewangeliczny charakter” i jakoby stanowi profanację tematu religijnego ${ }^{20}$. Ostatnią wieczerzę ostro skrytykował także Fiodor Dostojewski, oskarżając malarza o to, że wybrał styl niedostosowany do poważnego tematu obrazu, wprost opierając się na oświeceniowej koncepcji o hierarchii tematów ikonograficznych ${ }^{21}$.

Zdaniem G. Kobrzenieckiej-Sikorskiej, sytuacja, która ukształtowała się w rosyjskim malarstwie ikonowym w XIX w., w sposób nader dobitny pokazuje pewną tendencję społeczną - pogłębianie się przepaści pomiędzy „ludem rosyjskim” a wyższymi warstwami

\footnotetext{
17 B. Dąb-Kalinowska, Między Bizancjum..., s. 25.

18 Eadem, ,Mistrz życiodajnego pędzla”. Rafael w Rosji XIX wieku, w: eadem, Ikony i obrazy, Warszawa 2000, s. 214.

19 А. Г. Верещагина, Критики и искусство. Очерки истории русской художественной критики середины XVIII - первой трети ХIX века, Москва 2004, s. 583.

20 Н. И. Беспалова, op. cit., s. 26-27.

21 Ф. М. Достоевский, По поводу выставки, w: idem, Полное собрание сочинений в тридцати томах, t. 21, Ленинград 1980, s. 74.
} 
społecznymi i inteligencją. Podczas gdy lud był wierny staroruskiej tradycji i estetyce, inteligencja przyjmowała za swoją zachodnioeuropejską estetykę, która przenikała do Rosji od czasów Piotra I ${ }^{22}$. Jeżeli się to weźmie pod uwagę, nie będzie już tak zaskakujące to, że wychowani w duchu zachodnioeuropejskiej estetyki rosyjscy inteligenci nieczęsto wypowiadali się o malarstwie ikonowym, a jeżeli już to czynili, ich wypowiedzi były z reguły niezwykle krytyczne. Szczególnie mocno krytykowana była „brzydota” ikon. W swojej znanej wypowiedzi o ikonach wybitny krytyk literacki Wissarion Bieliński stwierdził, że ikony są tak brzydkie, iż nadają się jedynie do tego, by przykrywać nimi naczynia ${ }^{23}$.

Według rosyjskiego filologa Walerija Lepachina znaczenie owej wypowiedzi Bielińskiego zasadza się na tym, iż dopóki ikona jest nowa, jest wykorzystywana jako obraz modlitewny, a później, gdy poczernieje od starości, można wykorzystać ją po prostu w charakterze deski ${ }^{24}$. Bieliński stracił wiarę i można byłoby powiedzieć, że jego ocena malarstwa ikonowego jest spowodowana negatywnym stosunkiem do prawosławia, ale jeżeli przyjąć, że większość wytwarzanych w XIX w. ikon to były albo „krasnuszki”, albo „ikony podokładnicowe”, to słowa Bielińskiego nie będą się już wydawały takk dziwne, tym bardziej, że o niskiej jakości artystycznej współczesnych ikon pisali także tacy prawosławni autorzy, jak chociażby Fiodor Dostojewski i Nikołaj Leskow. Szczególnie ten ostatni w swojej publicystyce z lat 70. XIX w. niejednokrotnie podkreślał, że rosyjskie malarstwo ikonowe znajduje się w stanie upadku i trzeba je ,odrodzić”.

$$
* * *
$$

W związku z powstaniem mody na ,style historyczne”, poczynając od lat 8o. XIX w., w Rosji coraz częściej jest wysuwany postulat „odrodzenia malarstwa ikonowego”, obecny wszakże już od XVI w., od czasów Stogławego Soboru ${ }^{25}$. W latach 70., 80. i 90. kilkakrotnie podejmowano próby stworzenia nowego „podlinnika ikonopisarskiego”, który stanowiłby swego rodzaju podręcznik dla malarzy ikon, zawierający „prawidłowe” schematy kompozycyjne ikon ${ }^{26}$. To właśnie pragnienie „odrodzenia” rosyjskiego malarstwa ikonowego stało się główną przyczyną, która pobudziła cara Mikołaja II do utworzenia Komitetu Troski o Rosyjskie Malarstwo Ikonowe (I9OI-I9I7). Oficjalnym celem Komitetu miało być rozpowszechnianie „dobrej” (tradycyjnie prawosławnej) ikonografii przy jednoczesnej poprawie estetyki ikon. Nowa instytucja miała dość szeroki zakres działalności. Zajmujący stanowisko zarządcy Komitetu akademik Nikodim Kondakow zajął się przygotowaniem do druku kolejnych tomów ilustrowanego „podlinnika” ikonopisarskiego, otwarto także wzorcowe szkoły ikonopisarskie

\footnotetext{
22 G. Kobrzeniecka-Sikorska, op. cit., s. 150.

23 В. В. Белинский, Письмо к Гоголю, w: Литературное наследие, t. 54, s. 576.

24 В. В. Лепахин, Русь иконная. Лирическое введение в тему, w: idem, Икона в русской художественной литературе, Москва 2002, s. 29.

25 Zob. Л. А. Черная, Борьба с „плохописанием” икон в России в XVI-XVII столетиях, w: Русское искусство в контексте мировой художественной культуры. Научная конференция к 70-летию Музея им. Андрея Рублева, 12-14 декабря 2017 года, сост.и ред. И. А. Орецкая, Москва 2018, s. 82-88.

26 Zob. Сводный иконописный подлинник ХVIII века по списку Г. Филимонова, Москва 1874; Русский иконописный толковый подлинник, издаваемый И. Я. Красницким, Санкт-Петербург 1886; Д. А. Григоров, Русский иконописный подлинник, Санкт-Петербург 1887; Н. В. Покровский, Сийский иконописный подлинник, Санкт-Петербург 1895-1898.
} 
w Palechu, Msterze, Chołuju i Borysowce ${ }^{27}$. Chociaż ze względu na problemy finansowe po rewolucji 1905 r. działalność Komitetu Troski o Rosyjskie Malarstwo Ikonowe stopniowo zamiera, trudno przecenić jego znaczenie dla rozwoju rosyjskiego malarstwa ikonowego. Działania Komitetu Troski o Rosyjskie Malarstwo Ikonowe na równi z pierwszą wystawą rosyjskiego malarstwa ikonowego w I9Io r. wywołały ogromne zainteresowanie ikoną rosyjską w samej Rosji, jak i poza jej granicami. W drugim dziesięcioleciu XX w. refleksją teologiczną na temat ikony zaczęli się poważnie zajmować ojciec Siergiej Bułgakow ${ }^{28}$ i ojciec Paweł Fłorenski ${ }^{29}$, których koncepcje wywarły znaczący wpływ na powstanie w latach 50. XX w. nurtu teologicznego, który częściowo opierał się na idei „niepodobnego podobieństwa” Pseudo-Dionizego Aeropagity i został nazwany ,teologią ikony”30.

\section{Between tradition and modernity. Russian icons in $19^{\text {th }}$ century Abstract}

The aim of this article is to address the polemics about the long-standing stereotype in the history of art that Russian iconic paintings of the Igth century were secondary and mediocre in artistic terms and, therefore, of little interest for researchers. The author tries to show that this stereotype was largely created by Russian intellectuals of the second half of the nineteenth century, who betray an extremely critical attitude to contemporary iconic painting, despite the fact that the overall picture of Russian iconic painting of the nineteenth century is very complex and combines features of different visual traditions. The author defends the thesis that in the Russian iconic painting of the nineteenth century, tradition and contemporaneity are seamlessly combined, visible both at the level of theological reflection and at the level of artistic performance, and also that the nineteenth century is characterized by the ever-widening difference between the so-called folk icon" ("krasnuszka") and the aesthetics of intellectual elites, shaped under the influence of realistic Western European painting.

Key words: icon, Russia, icon painting, "krasnuszka”, Palekh

\section{BIBLIOGRAFIA}

Алленов М. М., Александр Андреевич Иванов, Москва 1980.

Белинский В. В., Письмо к Гоголю, w: Литературное наследие, t. 54, s. 576.

Беспалова Н. И., Русские революиионные демократы и передовая художественная критика в России І860-х годов, w: Русская прогрессивная художественная критика

\footnotetext{
27 Więcej na temat działalności Komitetu Troski o Rosyjskie Malarstwo Ikonowe zob. О. Ю. Тарасов, Русская икона в Серебряном веке. Из истории Комитета попечительства о русской иконописи (1901-1918), „Искусствознание”, 2010, nr 3-4, s. 461-468; idem, The Russian Icon and the Culture of the Modern: The Renaissance of Popular Icon Painting in the Reign of Nicholas II, ,Experiment. A Journal of Russian Culture”, 2001, nr 7, s. 71-101.

28 С. Н. Булгаков, Икона и иконопочитание, Париж 1931.

29 П. А. Флоренский, Иконостас. Избранные труды по искусству, Санкт-Петербург 1993.

30 „Teologia ikony” zdobyła szeroką popularność dzięki książce emigracyjnego rosyjskiego teologa Leonida Uspienskiego, zob. L. Ouspensky, La théologie de l'icône dans l'Église orthodoxe, Paris 1960.
} 
второй половины XX-начала XХ века: Хрестоматия, ред. В. В. Ванслов, Москва I977.

Брюсова В. Г., Русская живопись XVII века, Москва 1986.

Булгаков С. Н., Икона и иконопочитание, Париж І93I.

Черная Л. А., Борьба с „плохописанием” икон в России в XVI-XVII столетиях, w: Русское искусство в контексте мировой художественной культуры. Научная конференция к 7о-летию Музея им. Андрея Рублева, I2-I4 декабря 2017 года, сост.и ред. И. А. Орецкая, Москва 20I8, s. 82-88.

Dąb-Kalinowska B., Między Bizancjum a Zachodem. Ikony rosyjskie XVII-XIX wieku, Warszawa I990.

Dąb-Kalinowska B., ,,Mistrz życiodajnego pędzla”. Rafael w Rosji XIX wieku, w: eadem, Ikony $i$ obrazy, Warszawa 2000, s. 206-2I6.

Достоевский Ф. М., По поводу выставки, w: idem, Полное собрание сочинений в тридцати томах, t. 2I, Ленинград I980, s. 68-77.

Флоренский П. А., Иконостас. Избранные труды по искусству, Санкт-Петербург 1993.

Горький М., Детство; В людях; Мои университетьл, Москва 1973.

Григоров Д. А., Русский иконописный подлинник, Санкт-Петербург I887.

Kobrzeniecka-Sikorska G., Ikona, kult, polityka. Rosyjskie ikony maryjne od drugiej połowy XVII wieku, Olsztyn 2000.

Лепахин В. В., Икона в русской художественной литературе, Москва 2002.

Nichols R., The Icon and the Machine in Russia's religious Renaissance, w: Christianity and the Arts in Russia, red. W. Blumfield, Cambridge I99I, s. I3I-I44.

Ouspensky L., La théologie de l'icône dans l'Église orthodoxe, Paris 1960.

Покровский Н. В., Сийский иконописный подлинник, Санкт-Петербург I895-I898.

Русский иконописный толковый подлинник, издаваемый И. Я. Красницүки, СанктПетербург I886.

Тарасов О. Ю., Икона и благочестие. Очерки иконного дела в Императорской России, Москва 1995 .

Тарасов О. Ю., „Расхожая” икона в русской художественной культуре XVIII-начала ХХ века, w: Культура средних веков и Нового времени, Москва I987, s. 80-85.

Тарасов О. Ю., Русская икона в Серебряном веке. Из истории Комитета попечительства о русской иконописи (I9оI-I9I8), „Искусствознание”, 20Iо, nr 3-4, s. 46I-468.

Тарасов О. Ю., The Russian Icon and the Culture of the Modern: The Renaissance of Popular Icon Painting in the Reign of Nicholas II, „Experiment. A Journal of Russian Culture”, 200I, nr 7, s. 7I-IOI.

Stempczyńska B., Dostojewski a malarstwo, Katowice 1980.

Сводный иконописный подлинник ХVIII века по списку Г. Филимонова, Москва I874.

Шмидт Л. П., Золочение, серебрение и бронзирование по дереву, Москва 1903.

Верещагина А. Г., Критики и искусство. Очерки истории русской художественной критики середины XVIII - первой трети XIX века, Москва 2004.

Высочайше учрежденный Комитет попечительства о русской иконописи и его задачи, Санкт-Петербург 1907. 